Article

\title{
Scrubbing and Inhibiting Coagulation Effect on the Purification of Natural Powder Quartz
}

\author{
Xin Du ${ }^{\mathbb{D}}$, Chao Liang, Donglai Hou, Zhiming Sun * ${ }^{\mathbb{D}}$ and Shuilin Zheng *
}

School of Chemical and Environmental Engineering, China University of Mining and Technology (Beijing), Beijing 100083, China; dxcumtb@163.com (X.D.); lccumtb@163.com (C.L.); hdlcumtb@163.com (D.H.)

* Correspondence: zhimingsun@cumtb.edu.cn (Z.S.); zhengsl@cumtb.edu.cn (S.Z.); Tel.: +86-10-62339920 (Z.S.)

Received: 27 January 2019; Accepted: 19 February 2019; Published: 26 February 2019

\begin{abstract}
The low removal efficiency of fine clay impurities in natural powder quartz (NPQ) is the main problem that affects the practical utilization of this natural resource. In this work, detailed characterizations of NPQ and clay impurities in NPQ were analyzed by SEM-EDS, mineral liberation analysis (MLA) and impurities distribution analysis. A combined physical purification process, including sieving, scrubbing and centrifugation, was applied to remove the clay impurities. It was observed that the fine clay impurities adhering on quartz surface were effectively liberated by scrubbing, and the content of $\mathrm{Fe}_{2} \mathrm{O}_{3}$ and $\mathrm{Al}_{2} \mathrm{O}_{3}$ in the concentrate decreased from $0.48 \%$ and $0.40 \%$ to less than $0.01 \%$ and $0.02 \%$ at $\mathrm{pH} 9.3$ or when the dosage of sodium hexametaphosphate (SHMP) was $1 \times 10^{3} \mathrm{~g} / \mathrm{t}$. The coagulation interaction between quartz and impurities including hematite and orthoclase were analyzed based on the classical Deyaguin-Landau-Verwey-Overbeek (DLVO) theory. The results indicated that the main coagulation affecting the separation efficiency was the heterocoagulation between quartz and impurities and homocoagulation among hematite particles. Furthermore, adding regulators such as sodium hydroxide $(\mathrm{NaOH})$ or SHMP could significantly decrease the zeta potential of minerals and thus increase the total interaction energy $\left(V_{T}\right)$, which could effectively improve the dispersion of these fine impurity particles, and consequently improve the removal efficiency of impurities. Reverse increase of the zeta potential of minerals in strongly alkaline solutions or excessive SHMP were detected, which was likely the main factor limiting the further improvement of the purification efficiency.
\end{abstract}

Keywords: natural powder quartz; scrubbing; centrifugation; DLVO theory; coagulation

\section{Introduction}

Quartz is a highly critical and strategic material for advanced and emerging industrial technologies, which can be used extensively in advanced manufacturing of materials such as optical fibers, semi-conduct materials, highly pure glass in aerospace, etc. [1,2]. Considering the constant demand for better living standards of the increasing population, more and more quartz resources will be required in the future. Among different natural quartz resources, crystal is still the first choice for high purity quartz preparation. However, high purity crystal resources are rare in the world. Hence, researchers have tried to purify other natural quartz resources such as quartzite, quartz sand and white sand as substitutes [3,4]. In order to remove impurities, various processing methods were used. Physical methods such as magnetic separation, reverse flotation [5,6], and chemical treatment such as acidic leaching by hydrogen fluoride (HF) combined with other different fractions strong industrial acids such as $\mathrm{HCl}, \mathrm{HNO}_{3}$ or $\mathrm{H}_{2} \mathrm{SO}_{4}$ [2,7] were usually employed. In addition, some other new purification methods were also proposed, including bioleaching, supersonic-enhanced leaching and microwave explosion [8,9]. Because of the scarcity of high-quality resources and the high processing costs, developing feasible and economical processing technology is especially important. 
NPQ is a natural quartzose material which is widely distributed in China; it is formed by the the weathering of quartzite [10]. The characteristics of this resource include about $97-99 \% \mathrm{SiO}_{2}$, integrity granular shape and extremely fine grain ( $D_{90}$ is approximately $67 \mu \mathrm{m}$ and $D_{50}$ is around $39 \mu \mathrm{m}$ ) compared with other quartz resource. However, this resource is contaminated by different contents of impurities such as $\mathrm{Fe}_{2} \mathrm{O}_{3}$ and $\mathrm{Al}_{2} \mathrm{O}_{3}$ coming from fine clay minerals, which might significantly limit its application. Additionally, these fine clay impurities generated in the weathering course or exploitation are difficult to remove.

The traditional purification methods for NPQ include elutriation, flushing by quantitative water and spontaneous precipitation in a settling basin [11]. However, these methods have low separating efficiencies and high operation costs in practical applications. With the improvement in separation technologies, some methods such as magnetic separation and reverse flotation were applied for the purification of NPQ $[12,13]$. However, all these reported methods were inefficient for the removal of fine clay minerals in NPQ. The main reason for the low removal efficiency is that the impurity contents were so scarce that they could not be definitively distinguished by traditional methods, which limited advances in purification methods. On the other hand, chemical treatment with excellent desliming effect has disadvantages, such as high operation costs and acid wastewater discharge, causing environmental problems, etc. Hence, the efficient utilization of NPQ resources on a large scale was delayed. Therefore, the removal of fine clay impurities from NPQ by an effective, environmentally friendly and affordable process is particularly critical for the large scale industrial utilization of NPQ.

Attrition scrubbing has been used as a physical decontamination treatment in many fields of mineral purification, especially in the removal of clay impurities from target mineral surfaces [14-16]. Centrifugal separation is one of the cost-effective solutions for the treatment of waste water, flotation slurries and chemical industry $[17,18]$. Hence, it is expected that the scrubbing-centrifugation technology could be an ideal method for the removal of clay impurities in NPQ.

In this paper, the feasibility of a combination technique of sieving, scrubbing and centrifugal separation on the removal of clay impurities in NPQ was investigated. In order to purify NPQ more efficiently, both $\mathrm{NaOH}$ and SHMP were added as regulators in the purification process. Furthermore, the possible mechanisms were also proposed by studying the heterocoagulation and homocoagulation between quartz and impurity particles according to the DLVO theory.

\section{Materials and Methods}

\subsection{Materials}

The raw ore of NPQ used in this study was obtained from JiangXi province, China. The main chemical composition was measured by ICP-AES (inductively-coupled plasma atomic emission spectrometry) and the result is presented in Table 1. As shown in Table 1, NPQ is mainly composed of $\mathrm{SiO}_{2}(98.88 \%)$, and the main impurities are $\mathrm{Al}_{2} \mathrm{O}_{3}(0.48 \%)$ and $\mathrm{Fe}_{2} \mathrm{O}_{3}(0.19 \%)$; there are some other impurities like $\mathrm{TiO}_{2}, \mathrm{CaO}$, and $\mathrm{MgO}$, etc. X-ray diffraction (XRD) was used to examine the purity of raw ore; the XRD pattern are presented in Figure 1. Figure 1 shows that the main peaks match well with the standard quartz peaks. However, no clear impurity peaks were observed, since the impurity content is too low, i.e., it exceeded the detection limit of XRD analysis.

Table 1. Chemical analysis of the dry NPQ (wt \%).

\begin{tabular}{cccccccccc}
\hline Compositions & $\mathrm{SiO}_{2}$ & $\mathrm{Al}_{2} \mathrm{O}_{3}$ & $\mathrm{Fe}_{2} \mathrm{O}_{3}$ & $\mathrm{TiO}_{2}$ & $\mathrm{CaO}$ & $\mathrm{MgO}$ & $\mathrm{K}_{2} \mathrm{O}$ & $\mathrm{Na}_{2} \mathrm{O}$ & L.O.I. ${ }^{\mathrm{a}}$ \\
\hline Content (wt \%) & 98.88 & 0.48 & 0.19 & 0.03 & 0.06 & 0.04 & 0.04 & 0.05 & 0.24 \\
\hline \multicolumn{8}{c}{${ }^{a}$ Loss on ignition. }
\end{tabular}




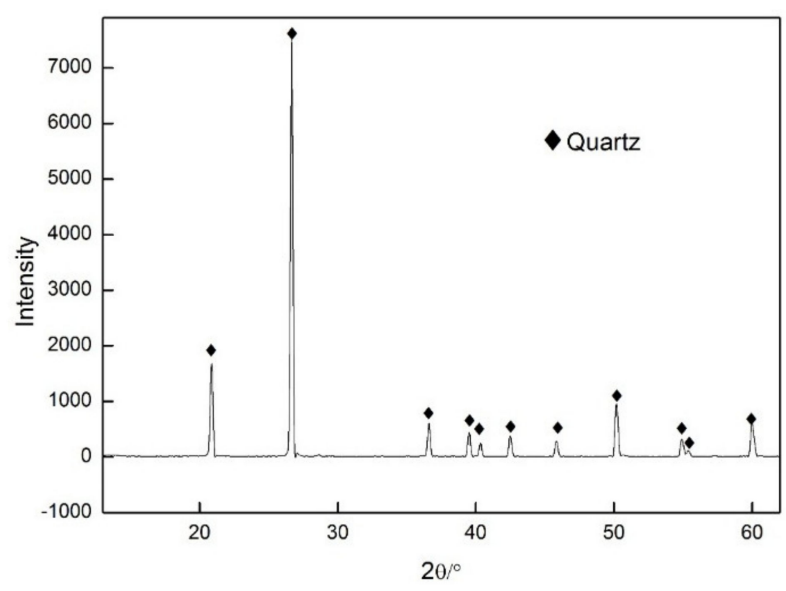

Figure 1. XRD pattern of NPQ.

All the reagents used in this study were chemically pure and purchased from Beijing Chemical Reagent Company (Beijing, China). Distilled water was used throughout the experiments.

\subsection{Purification Methods}

Highly concentrated (about 75\%) pulp was prepared by adding $175 \mathrm{~g}$ water to $500 \mathrm{~g}$ raw ore, and then scrubbing tests were performed in vessels for about $25 \mathrm{~min}$ with the stirring rate of $1500 \mathrm{rpm}$. An appropriate amount of regulators ( $\mathrm{NaOH}$ or SHMP) was pre-dissolved in $5 \mathrm{~mL}$ of water and then added to the scrubbing suspension at room temperature. After scrubbing, the pulp was stirred and dispersed for $5 \mathrm{~min}$ with extra $1750 \mathrm{~mL}$ water before being sieved using a 200 mesh standard screen $(75 \mu \mathrm{m})$; the oversized product was tailing and labelled as "T1". The under-sized product was centrifuged at $315 \mathrm{rpm}$ (RCF (relative centrifugal force) $=10$ ) for $1 \mathrm{~min}$. The sediment of centrifugation was concentrated and labelled "Con", and the suspension of centrifugation was tailing and labelled "T2". All products were dried and weighed for analysis.

\subsection{Equipment}

The chemical compositions of the raw NPQ and purification products were measured using an ICP-OES (Agilent730, Agilent Technologies, Santa Clara, CA, USA). The crystalline phase identification of samples were undertaken by X-ray diffraction analysis D8 ADVANCE (Bruker, Billerica, MA, USA), equipped with a $\mathrm{Cu}-\mathrm{K} \alpha$ radiation at a goniometer rate of $2 \theta=4^{\circ} / \mathrm{min}$ and the crystalline phase identification of trace impurities were detected by MLA. Microstructures were investigated by scanning electron microscopy (HT7700, Hitachi, Tokyo, Japan) at $10.0 \mathrm{KV}$, equipped with energy-dispersive microanalysis facilities (EDS). Zeta $(\zeta)$ potentials were measured using a Brookhaven zeta potential analyzer and three runs of measurement were conducted. The Mineral Liberation Analyser (MLA250, FEI, Hillsboro, OR, USA) was provided by Beijing General Research Institute of Mining \& Metallurgy (BGRIMM, Beijing, China).

\section{Results and Discussion}

\subsection{Impurity Analysis of NPQ}

In order to analyze the distribution of impurities in different sizable fractions, NPQ were first sieved using a set of standard screens (100, 200 and 325 mesh), and then the part of -325 mesh was divided into sediment and suspension by centrifugation at $315 \mathrm{rpm}$ for $1 \mathrm{~min}$. The yields and contents of $\mathrm{Fe}_{2} \mathrm{O}_{3}$ and $\mathrm{Al}_{2} \mathrm{O}_{3}$ in different sizes of NPQ are summarized in Table 2. As displayed in Table 2, the yields were $1.96 \%, 4.51 \%$ and $5.44 \%$ for +100 mesh, $-100 \sim+200$ mesh and micro-fine (centrifugal suspension) samples, respectively. The contents of $\mathrm{Fe}_{2} \mathrm{O}_{3}$ and $\mathrm{Al}_{2} \mathrm{O}_{3}$ in coarse grains are within the range of $0.132-0.301 \%$ and $0.157-0.862 \%$, and in micro-fine the contents of $\mathrm{Fe}_{2} \mathrm{O}_{3}$ and 
$\mathrm{Al}_{2} \mathrm{O}_{3}$ are $2.576 \%$ and $8.790 \%$, respectively. On the other hand, the yields of $-200 \sim+325$ mesh and the sediments of -325 mesh are $26.14 \%$ and $61.95 \%$ respectively with relatively lower content of impurities. It was concluded that the impurities of $\mathrm{Fe}_{2} \mathrm{O}_{3}$ and $\mathrm{Al}_{2} \mathrm{O}_{3}$ were mainly distributed in coarse grains (>200 mesh) and micro-fine grains.

Table 2. Yields and contents of $\mathrm{Fe}_{2} \mathrm{O}_{3}$ and $\mathrm{Al}_{2} \mathrm{O}_{3}$ in different sizable of NPQ.

\begin{tabular}{ccccc}
\hline \multirow{2}{*}{ Particle Size/Mesh } & \multirow{2}{*}{ Yield (\%) } & \multicolumn{2}{c}{ Content (\%) } \\
\cline { 3 - 5 } & & $\mathrm{Fe}_{\mathbf{2}} \mathbf{O}_{\mathbf{3}}$ & $\mathbf{A l}_{\mathbf{2}} \mathbf{O}_{\mathbf{3}}$ \\
\hline \multicolumn{2}{c}{+100} & 1.96 & 0.301 & 0.862 \\
\hline \multicolumn{2}{c}{$-100 \sim+200$} & 4.51 & 0.132 & 0.157 \\
\hline \multicolumn{2}{c}{$-200 \sim+325$} & 26.14 & 0.040 & 0.031 \\
\hline \multirow{2}{*}{-325} & sediments & 61.95 & 0.053 & 0.043 \\
\cline { 2 - 5 } & suspensions & 5.44 & 2.576 & 8.790 \\
\hline
\end{tabular}

SEM equipped with EDS analysis was used to directly observe the microstructural characteristics and confirm the elements compositions of clay particles existing in NPQ. As shown in Figure 2, the dispersion of quartz was very even and the particle sizes were approximately in the range of 20-55 $\mu \mathrm{m}$. Meanwhile, a large number of small particles $(1-3 \mu \mathrm{m})$ were found adhering to the quartz surface. The EDS analysis showed that the main elements of particles on the quartz surface are $\mathrm{Si}, \mathrm{O}$, $\mathrm{Al}$ and $\mathrm{Fe}$, indicating that the fine particles could be clay impurities.

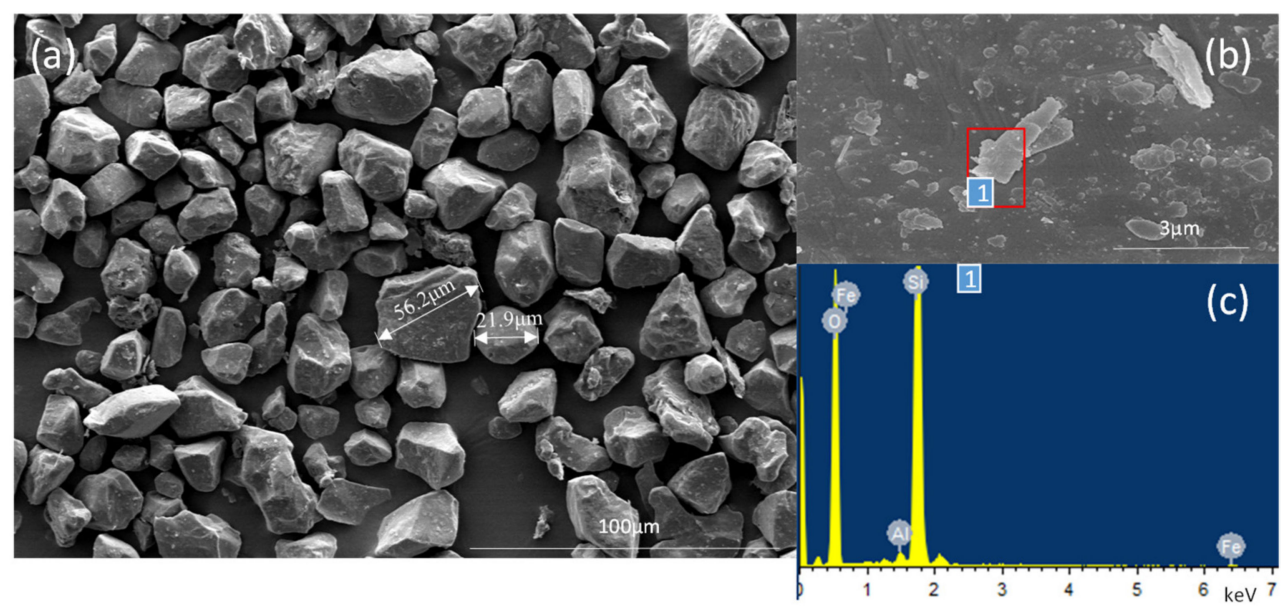

Figure 2. (a) SEM image of NPQ, (b) SEM image of impurity adhering on quartz surface, (c) EDS of impurity.

Mineral liberation analysis (MLA) is a commercially available SEM-based image analysis system which has been widely applied in mineralogy and metallurgical processing $[19,20]$. Each mineral grain delineation inside the grain can be identified automatically with single X-ray analysis. The SEM-based image (BSE) signal in MLA has higher spatial resolution $(0.1-0.2 \mu \mathrm{m})$ than X-ray of $2-5 \mu \mathrm{m}$. Hence, the mineralogy and the content of impurities in NPQ could not be determined by XRD because of the limitations of analytical accuracy, but could be determined by MLA. The representative results are displayed in Figures 3 and 4, and the distribution of $\mathrm{Fe}_{2} \mathrm{O}_{3}$ and $\mathrm{Al}_{2} \mathrm{O}_{3}$ according to mineralogy semi-quantitatively is summarized in Table 3. It was revealed that the presence of $\mathrm{Fe}_{2} \mathrm{O}_{3}$ comes mainly from hematite, and $\mathrm{Al}_{2} \mathrm{O}_{3}$ comes from orthoclase and anorthose. In addition, impurities such as mica were present in the sample. 


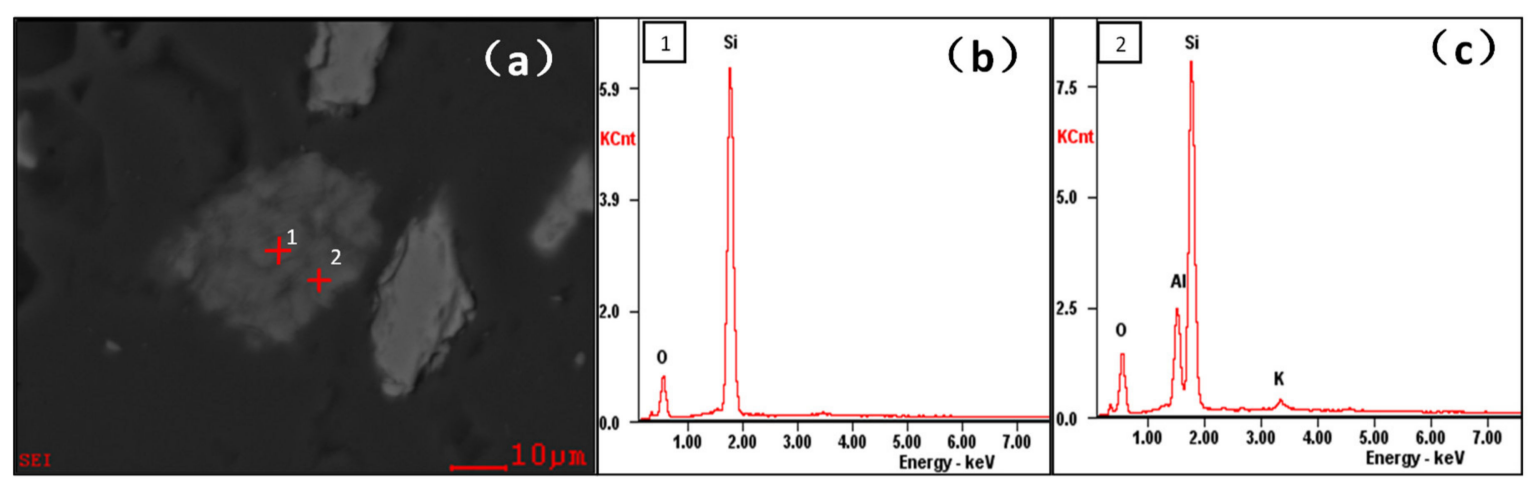

Figure 3. SEI image and spectrum of orthoclase in NPQ. (a) SEI image of quartz and orthoclase, (b) Energy spectrum of quartz, (c) Energy spectrum of orthoclase.

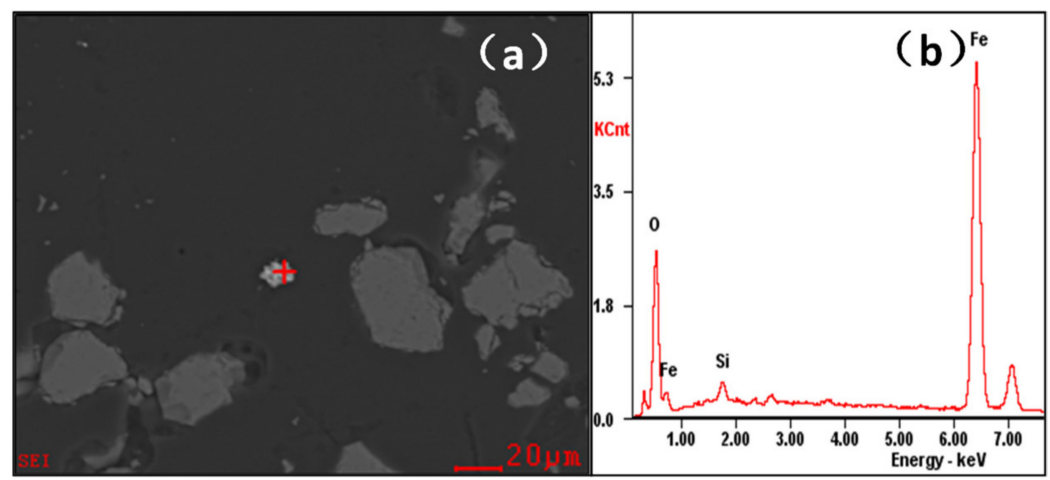

Figure 4. SEI image and spectrum of hematite in NPQ. (a) SEI image of hematite, (b) Energy spectrum of hematite.

Table 3. Distribution of $\mathrm{Al}_{2} \mathrm{O}_{3}$ and $\mathrm{Fe}_{2} \mathrm{O}_{3}$ at different minerals in NPQ detected by MLA (\%).

\begin{tabular}{cccccc}
\hline Impurities & Hematite & Orthoclase & Anorthose & Mica & Total \\
\hline $\mathrm{Fe}_{2} \mathrm{O}_{3}$ & 92.17 & 0 & 0 & 7.83 & 100 \\
$\mathrm{Al}_{2} \mathrm{O}_{3}$ & 0 & 64.42 & 26.53 & 9.06 & 100 \\
\hline
\end{tabular}

\subsection{Effects of Scrubbing and Regulators on Impurities Removal}

According to the character of impurities existing in the sample, a series of experiments were conducted as displayed in Table 4 to explore the effect of scrubbing and regulators on impurity removal. Firstly, experiments with and without scrubbing were performed. Subsequently, different regulators were added to the pulp when scrubbing. Test No. 1 was stirred 25 min with equivalent water and separated under the same condition as the test No. 2. The yields and element contents of $\mathrm{Fe}_{2} \mathrm{O}_{3}$ and $\mathrm{Al}_{2} \mathrm{O}_{3}$ in different products are summarized in Table 4.

The results displayed that the content of $\mathrm{Fe}_{2} \mathrm{O}_{3}$ and $\mathrm{Al}_{2} \mathrm{O}_{3}$ in concentrate without scrubbing decreased from $0.048 \%$ and $0.040 \%$ to $0.020 \%$ and $0.033 \%$ after scrubbing, respectively. Adding $\mathrm{NaOH}$ or SHMP when scrubbing could further decrease the content of $\mathrm{Fe}_{2} \mathrm{O}_{3}$ in concentrate to around $100 \mu \mathrm{g} / \mathrm{g}(0.01 \%)$ and the content of $\mathrm{Al}_{2} \mathrm{O}_{3}$ to around $200 \mu \mathrm{g} / \mathrm{g}(0.018-0.024 \%)$. The yield of both $\mathrm{T} 2$ and concentrate with scrubbing increased from $5.44 \%$ and $88.09 \%$ to $5.85 \%$ and $89.63 \%$, and the yield of $\mathrm{T} 1$ decreased from $6.47 \%$ to $4.52 \%$. Compared with scrubbing without regulators, adding regulators has little effect on the yields of products. 
Table 4. Experiments conditions and results.

\begin{tabular}{|c|c|c|c|c|c|c|}
\hline \multirow{2}{*}{ No. } & \multirow{2}{*}{ Regulator } & \multirow{2}{*}{$\begin{array}{l}\text { Dosage } \\
/\left(\mathrm{g} \cdot \mathrm{t}^{-1}\right)\end{array}$} & \multirow{2}{*}{ Product } & \multirow{2}{*}{ Yield (\%) } & \multicolumn{2}{|c|}{ Impurity Content (\%) } \\
\hline & & & & & $\mathrm{Fe}_{2} \mathrm{O}_{3}$ & $\mathrm{Al}_{2} \mathrm{O}_{3}$ \\
\hline \multirow{3}{*}{1} & \multirow{3}{*}{ / } & \multirow{3}{*}{ / } & $\mathrm{T} 1$ & 6.47 & 0.182 & 0.365 \\
\hline & & & $\mathrm{T} 2$ & 5.44 & 2.551 & 7.76 \\
\hline & & & Con & 88.09 & 0.048 & 0.04 \\
\hline \multirow{3}{*}{2} & \multirow{3}{*}{ / } & \multirow{3}{*}{ / } & $\mathrm{T} 1$ & 4.52 & 0.173 & 0.311 \\
\hline & & & $\mathrm{T} 2$ & 5.85 & 2.857 & 7.51 \\
\hline & & & Con & 89.63 & 0.020 & 0.033 \\
\hline \multirow{3}{*}{3} & \multirow{3}{*}{$\mathrm{NaOH}$} & \multirow{3}{*}{500} & $\mathrm{~T} 1$ & 4.33 & 0.141 & 0.179 \\
\hline & & & $\mathrm{T} 2$ & 6.03 & 2.948 & 7.602 \\
\hline & & & Con & 89.64 & 0.010 & 0.018 \\
\hline \multirow{3}{*}{4} & \multirow{3}{*}{ SHMP } & \multirow{3}{*}{500} & $\mathrm{~T} 1$ & 4.38 & 0.148 & 0.169 \\
\hline & & & $\mathrm{T} 2$ & 6.02 & 2.963 & 7.521 \\
\hline & & & Con & 89.60 & 0.010 & 0.024 \\
\hline
\end{tabular}

The impurity distribution ratio $(P)$ in different products under different conditions was calculated according Equation (1), which revealed the impurity change from a comprehensive view of content and yield, where $Y_{P r o}$ and $G_{P r o}$ represent the yield and the contents of $\mathrm{Fe}_{2} \mathrm{O}_{3}$ or $\mathrm{Al}_{2} \mathrm{O}_{3}$ in different products respectively, and $C_{\text {raw }}$ represents the impurity content in raw ore.

$$
P=\frac{Y_{\text {Pro }} \times G_{P r o}}{C_{\text {raw }}} \times 100 \%
$$

The results in Figure 5 suggest that $P_{\mathrm{Fe} 2 \mathrm{O} 3}$ and $P_{\mathrm{Al} 2 \mathrm{O} 3}$ of $\mathrm{T} 1$ and concentrate all decreased significantly after scrubbing, and thus, the $P_{\mathrm{Fe} 2 \mathrm{O} 3}$ and $P_{\mathrm{Al} 2 \mathrm{O} 3}$ of $\mathrm{T} 2$ both increased. It could be inferred that the physical impact and shearing actions occurring between contaminated particles and either the liquid phase or the walls and impellers stripped the clay impurities from quartz surface and crushed the coarse grains as micro-size fractions. The increase of $P_{\mathrm{Fe} 2 \mathrm{O} 3}$ and $P_{\mathrm{Al} 2 \mathrm{O} 3}$ of $\mathrm{T} 2$ indicated that more impurities were separated into $\mathrm{T} 2$ by centrifugation. The experimental results of test No. 3 and 4 showed that the concentrations of both $P_{\mathrm{Fe} 2 \mathrm{O} 3}$ and $P_{\mathrm{Al} 2 \mathrm{O} 3}$ further decreased, indicating that the separation efficiency of clay impurities from NPQ was improved by adding NaOH or SHMP.
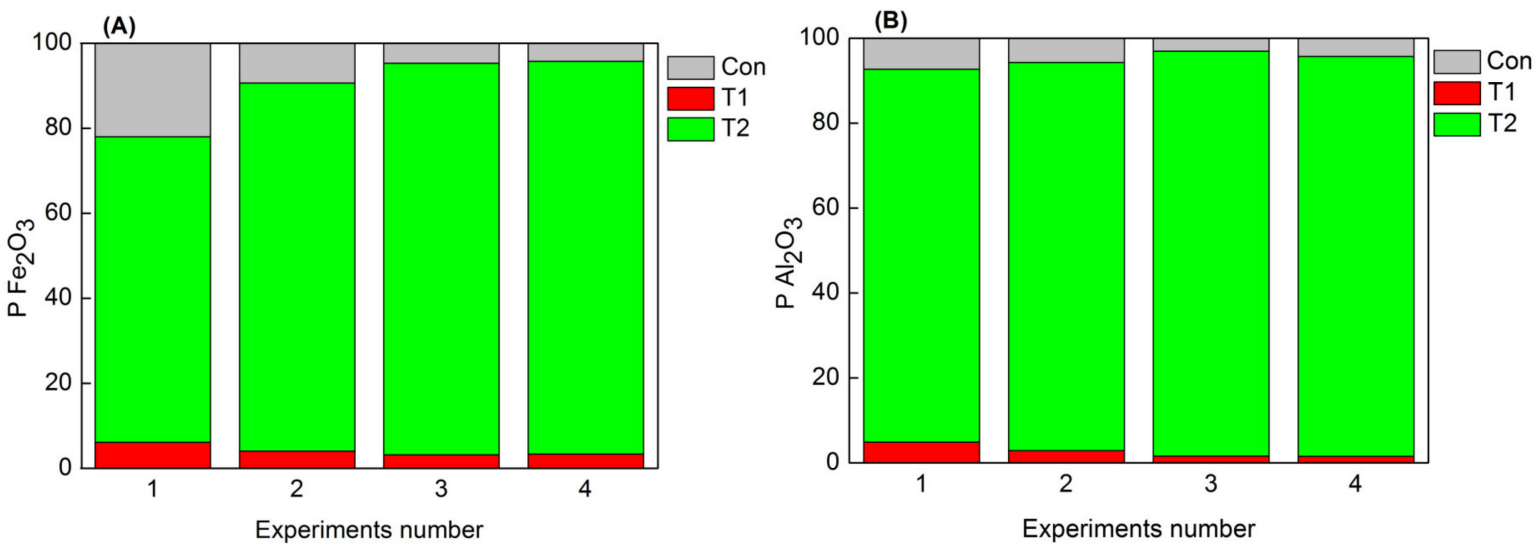

Figure 5. Distribution ratio of $\mathrm{Fe}_{2} \mathrm{O}_{3}(\mathbf{A})$ and $\mathrm{Al}_{2} \mathrm{O}_{3}(\mathbf{B})$ in $\mathrm{T} 1, \mathrm{~T} 2$ and concentrate (Con) at different experiment conditions.

Some representative SEM images shown in Figure 6 were applied to identify the effect of scrubbing and centrifugation on the clay impurity removal of NPQ. As displayed in Figure $6 \mathrm{c}, \mathrm{d}$, it is obvious that the fine clay particles adhering on quartz surface disappeared, and the surface was clearer and smoother after scrubbing compared with the samples which had not undergone scrubbing (Figure $6 a, b)$. It could 
be concluded that the impurity minerals were effectively stripped from the surface of quartz through scrubbing. According to Figure $6 \mathrm{e}, \mathrm{f}$, it was demonstrated that the fine particles were separated into the $\mathrm{T} 2$ by centrifugation, which is the key factor affecting the removal efficiency of the clay impurities.
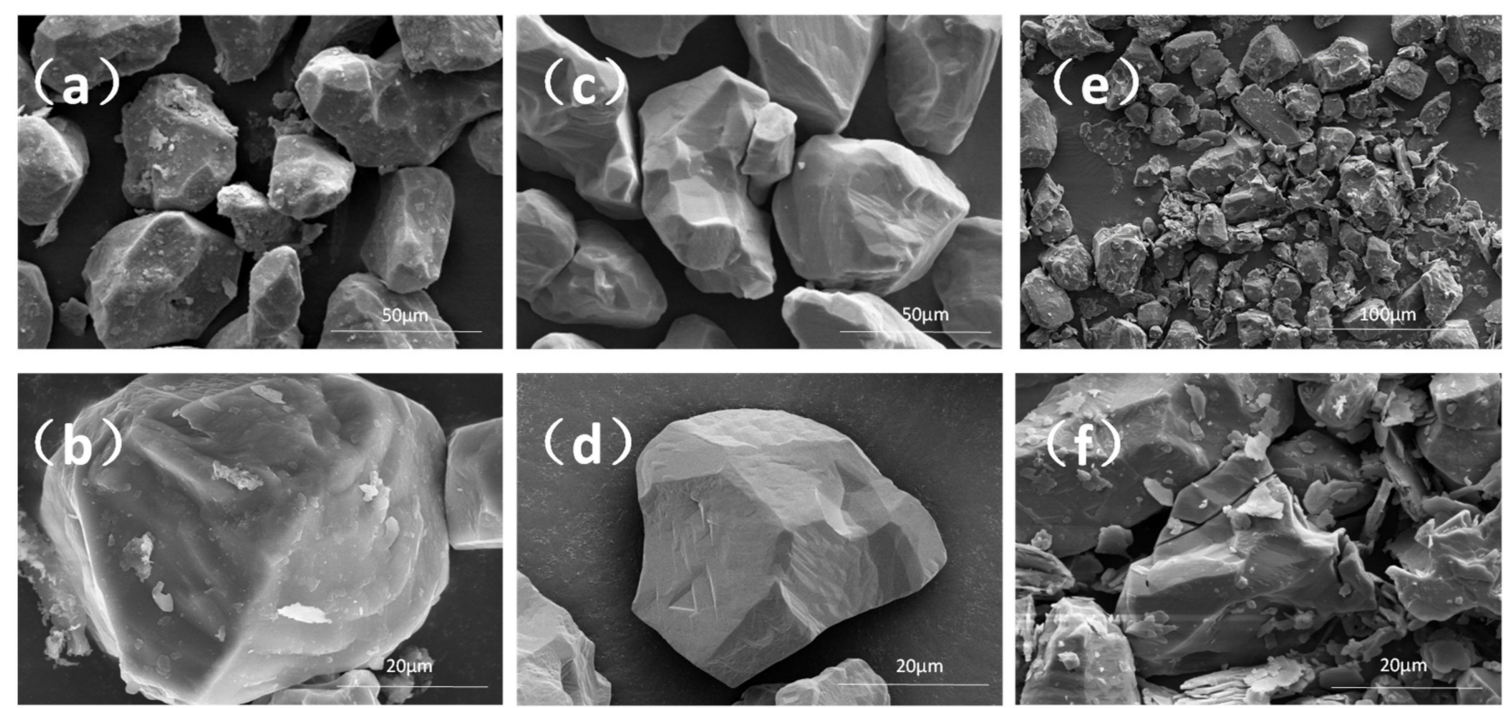

Figure 6. SEM images of concentrate and $\mathrm{T} 2$ in different conditions, $(\mathbf{a}, \mathbf{b})$ concentrate without scrubbing,

(c,d) concentrate with scrubbing, (e,f) T2 of No. 2.

\subsection{Effects of $p H$ and Dosage of SHMP on Impurities Removal}

To reveal the influence of $\mathrm{pH}$ on the removal efficiency of clay impurities, the impurities content of $\mathrm{Fe}_{2} \mathrm{O}_{3}$ and $\mathrm{Al}_{2} \mathrm{O}_{3}$ in concentrate were illustrated as a function of $\mathrm{pH}$ in Figure 7. The $\mathrm{pH}$ of solution was adjusted through adjusting $\mathrm{NaOH}$ amount, and the practical $\mathrm{pH}$ values were measured before centrifugation. The results showed that when the $\mathrm{pH}$ increased from 7.1 to 9.3 , both of the contents of $\mathrm{Fe}_{2} \mathrm{O}_{3}$ and $\mathrm{Al}_{2} \mathrm{O}_{3}$ decreased significantly, but the increase of $\mathrm{pH}$ from 9.3 to 11.7 only shows slight influence on impurities removal.

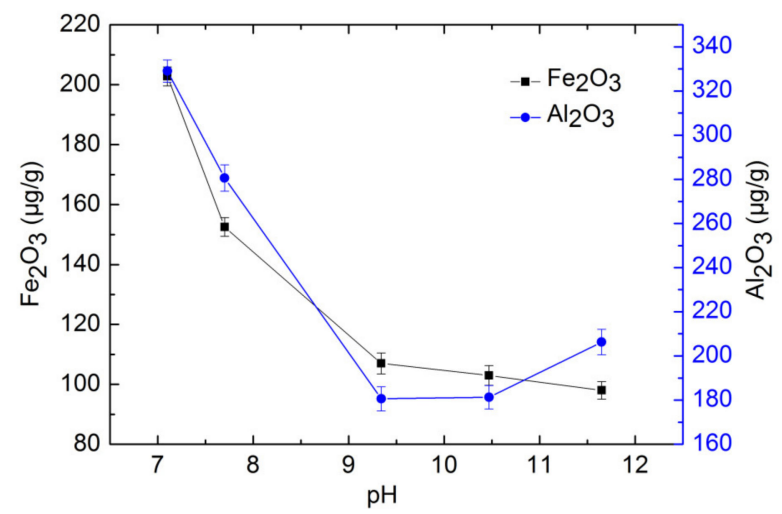

Figure 7. Effect of $\mathrm{pH}$ on the removal of impurities in concentrate.

The influence of SHMP on impurities removal was studied for dosages of 100, 500, 1000, 3000 and $5000 \mathrm{~g} / \mathrm{t}$ at $\mathrm{pH}=7$ and the results are given in Figure 8. As expected, the dosage of SHMP affects both of the content of $\mathrm{Fe}_{2} \mathrm{O}_{3}$ and $\mathrm{Al}_{2} \mathrm{O}_{3}$ in concentrate. The removal efficiency of impurities was improved with the dosage of SHMP increases from 100 to $1000 \mathrm{~g} / \mathrm{t}$, and an optimal effect can be obtained at $1000 \mathrm{~g} / \mathrm{t}$. However, with increasing the dosage of SHMP continuously, the content of both $\mathrm{Fe}_{2} \mathrm{O}_{3}$ and $\mathrm{Al}_{2} \mathrm{O}_{3}$ in the concentrate presented an increasing trend, which indicated that an excess of SHMP can inhibit the removal efficiency of impurities. 


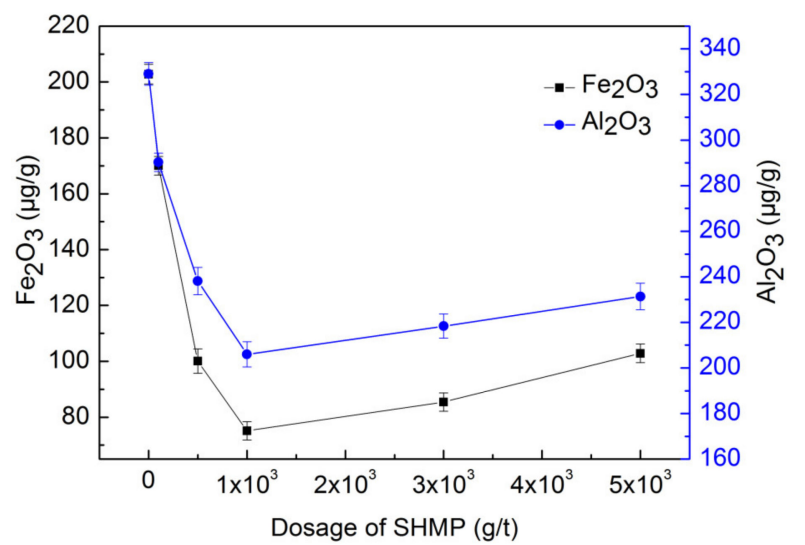

Figure 8. Effect of SHMP on the removal efficiency of impurities in concentrate.

\section{Purification Mechanism}

It is obvious that scrubbing enhanced the liberation of minerals, and the separation efficiency was dominated by centrifugation. Since previous experiments revealed that adding $\mathrm{NaOH}$ or SHMP could improve the removal efficiency of clay impurities, the mechanism was analyzed based on the influence of $\mathrm{NaOH}$ or SHMP on the interaction between quartz and clay impurity particles including hematite and orthoclase. Classical DLVO theory was used to study the stability of slurry and mineral particles by many researchers [21,22]. Based on the DLVO theory, the interactions between particles in aqueous solution include the van der Waals attraction force and the electrostatic double layer repulsive force. The coagulation and dispersion behaviors of mineral particles are mainly determined by the total interaction energy $\left(V_{T}\right)$, which is the sum of the London-van der Waals dispersion interaction energy $\left(V_{A}\right)$ and electrostatic repulsive energy $\left(V_{R}\right)$, i.e., Equation (2), and the interaction energy $V_{A}$ and $V_{R}$ between two spheres can be calculated by Equations (3) and (4) [23].

$$
\begin{gathered}
V_{T}=V_{R}+V_{A} \\
V_{R}=\frac{-A_{132}}{6 D} \frac{R_{1} R_{2}}{R_{1}+R_{2}} \\
V_{A}=\frac{\pi \varepsilon_{0} \in R_{1} R_{2}}{R_{1}+R_{2}}\left\{4 \varphi_{1} \varphi_{2} \ln \frac{1+e^{-k D}}{1-e^{-k D}}+\left\{\varphi_{1}^{2}+\varphi_{2}^{2}\right\} \ln \left\{1-e^{-2 k D}\right\}\right\}
\end{gathered}
$$

where $R_{1}$ and $R_{2}$ are the radius of two spheres, $D$ is the separation distance of two spheres. $A_{132}$ is the effective Hamaker constant of substances 1 and 2 interacting in medium 3; it can be calculated by Equation (5), using the Lifshitz approach based on quantum physics [24]. $\varphi_{1}$ and $\varphi_{2}$ are the surface potentials of substance 1 and 2 , which are substituted by the measured $\zeta$ potential value, $\kappa^{-1}$ is the double layer thickness $(9.6 \mathrm{~nm}$ in $1 \mathrm{mM} \mathrm{KCl}) . \varepsilon$ is the dielectric constant of the aqueous medium $\left(78.4 \mathrm{C}^{2} \cdot \mathrm{m} \cdot \mathrm{J}^{-1}\right), \varepsilon_{0}$ is the dielectric constant of vacuum $\left(8.854 \times 10^{-12} \mathrm{C}^{2} \cdot \mathrm{m} \cdot \mathrm{J}^{-1}\right)$, the dielectric constants of quartz, hematite and orthoclase are $4.3,6.9$ and 81 , respectively $[25,26]$.

$$
A_{\text {total }}=A_{v=0}+A_{v>0} \approx \frac{3}{4} k T\left(\frac{\varepsilon_{1}-\varepsilon_{3}}{\varepsilon_{1}+\varepsilon_{3}}\right)\left(\frac{\varepsilon_{2}-\varepsilon_{3}}{\varepsilon_{2}+\varepsilon_{3}}\right)+\frac{3 h v_{e}}{8 \sqrt{2}} \frac{\left(n_{1}^{2}-n_{3}^{2}\right)\left(n_{2}^{2}-n_{3}^{2}\right)}{\sqrt{\left(n_{1}^{2}+n_{3}^{2}\right)} \sqrt{\left(n_{2}^{2}+n_{3}^{2}\right)\left\{\sqrt{\left\{n_{1}^{2}+n_{3}^{2}\right\}}+\sqrt{\left\{n_{2}^{2}+n_{3}^{2}\right\}}\right.}}
$$

where $k_{B}$ is the Boltzmann constant $\left(1.381 \times 10^{-23} \mathrm{~J} \cdot \mathrm{K}^{-1}\right), T$ is the room temperature $(293.15 \mathrm{~K}), h$ is the Planck constant $\left(6.626 \times 10^{-34} \mathrm{~J} \cdot \mathrm{s}\right), v_{e}$ is the main electronic absorption frequency in the UV typically around $3 \times 10^{15} \mathrm{~s}^{-1}$ and $n$ is the refractive index. 


\subsection{Effects of $\mathrm{pH}$ on the Zeta Potential}

In this study, the standard minerals of hematite and orthoclase were selected as the main objects of impurity to analyze the processing mechanism. The standard minerals were obtained from commercial vendors. The quartz used in this paper was the concentrate of test No. 3, which was washed several times with distilled water. All the samples were ground and sieved by a 400 mesh for the test.

The $\zeta$ potentials of quartz, hematite and orthoclase were measured at different $\mathrm{pHs}$, from neutral to alkaline, with a fixed ionic strength of $1.0 \mathrm{mM} \mathrm{KNO}_{3}$. As shown in Figure 9, the $\zeta$ potentials of both hematite and orthoclase decreased as the $\mathrm{pH}$ increased, which were in agreement with the results reported by other researchers $[27,28]$. Unlike the characteristic of $\zeta$ potentials of hematite and orthoclase, one interesting feature has been observed from the plot of $\zeta$ potential of quartz. Initially, the $\zeta$ potential of quartz decreased as the $\mathrm{pH}$ increased from 7 to 9 . However, when the $\mathrm{NaOH}$ was added to the slurry to increase the $\mathrm{pH}$ above 9, this potential of quartz gradually increased; this phenomenon also has been detected by other researchers [29]. The possible reasons for the charge changing of quartz according to the reference could be explained as follows: the metal ions in solution and the clay particles coated on the quartz surface, or the solubility of quartz rises sharply with increasing the solution $\mathrm{pH}$, which could compressed the electric double layers of minerals, and thus, decreased the negative charge potentials [30-32].



Figure 9. The $\zeta$ potential of quartz $(\mathrm{Q})$, hematite $(\mathrm{H})$ and orthoclase $(\mathrm{O})$ as a function of $\mathrm{pH}$ at constant ionic strength of $1.0 \mathrm{mM} \mathrm{KNO}_{3}$.

\subsection{Heterocoagulation between Quartz and Impurities}

The interaction energy between quartz and impurity particles was calculated based on the DLVO theory firstly. It is important to emphasize that the impurity particles (radius $3 \mu \mathrm{m}$ ) and NPQ (radius $40 \mu \mathrm{m}$ ) were assumed as two ideal spheres and the measured $\zeta$ potential value as the surface potential. Figure 10 showed the interaction energy of $V_{R}, V_{A}$ and $V_{T}$ respectively between quartz and hematite $(\mathrm{Q}-\mathrm{H})$, quartz and orthoclase $(\mathrm{Q}-\mathrm{O})$ at different $\mathrm{pHs}$. When the separation distance was above $3 \mathrm{~nm}$, both of the $V_{T}$ of Q-H and Q-O were dominated by $V_{R}$, and thus, the values were positive as pHs varied from 7 to 11 , which suggested that the interaction between quartz and impurities was primarily repulsive in nature. It is also indicated that the $V_{T}$ change to negative with the $V_{A}$ tend to negative infinitely when interaction distance being much closer (less than $1 \mathrm{~nm}$ ), which means that the interaction force was attractive when the impurity particles adhering on quartz surface. The results also illustrated the importance of scrubbing, which provided sufficient energy to overcome the strong $V_{A}$ between quartz and impurities adhering on quartz surface. 

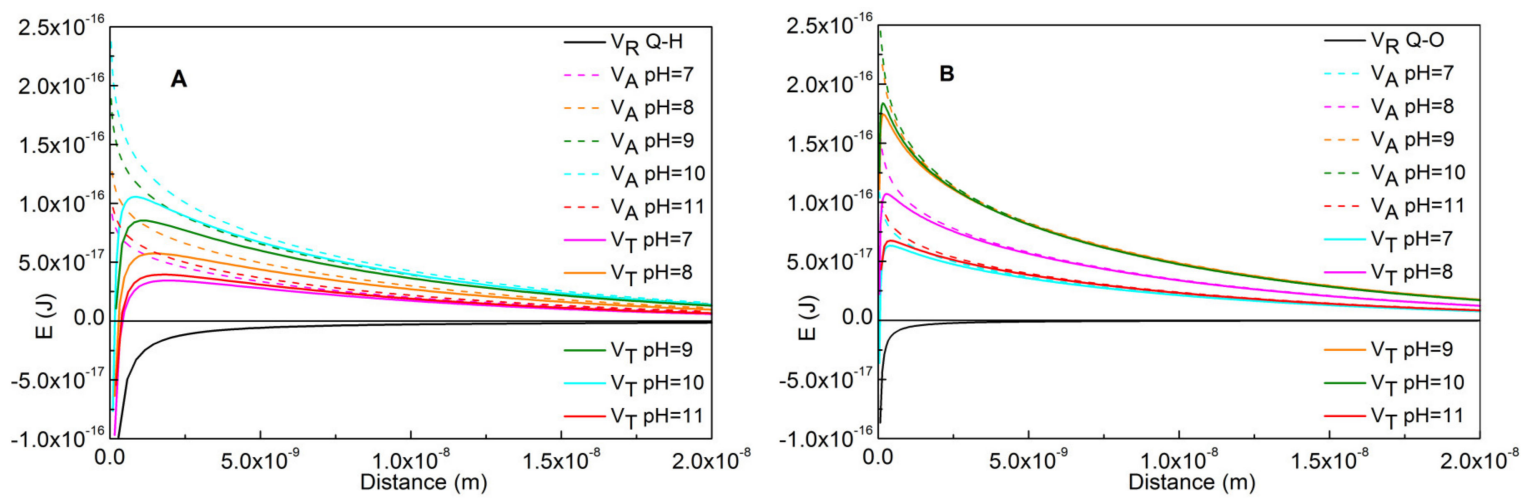

Figure 10. Relationship between interaction energy of impurities with quartz and particles distance at different $\mathrm{pH}$; (A) is the relationship of hematite with quartz; (B) is the relationship of orthoclase with quartz.

Although the $V_{T}$ between quartz and impurities always remained positive, the experimental results showed that the removal efficiency of impurities has a strong correlation with the changing of $V_{T}$. As can be seen, the $V_{T}$ was increased gradually with the $\mathrm{pH}$ increase from 7 to 9 , which is consistent with the changing trend of removal efficiency of impurities according to the previous experiments results. The reason could be explained that the $V_{T}$ was calculated based on the assumption that the averaging particle size of impurity was $3 \mu \mathrm{m}$, but the practical particle size should be normally distributed. According to Equation (2), $V_{T}$ is roughly proportional to the radius of impurity particle $R_{1}$ when the radius of quartz $R_{2}$ and the $\zeta$ potential of minerals are fixed. When the radius of impurity tends to $0, V_{T}$ also tends to zero, which means that there are always a certain proportion of fine impurity particles which could be attracted on the quartz surface easily, and the proportion of particles attached on quartz would decrease with the increase of $V_{T}$.

At $\mathrm{pH} 10$, even though the $\zeta$ potential of quartz displayed a reverse increase, $V_{T}$ keeps increasing as the $\zeta$ potentials of both hematite and orthoclase decreased, and the effect of $\mathrm{pH}$ from 9 to 10 on impurities removal is not notable. When $\mathrm{pH}$ was up to $11, V_{T}$ reduced significantly, and consequently, a worse impurity removal effect was observed. All the results indicated that increasing $V_{T}$ by adjusting $\mathrm{pH}$ could improve the impurities removal. However, the strong alkaline environment was not beneficial for impurity removal, as the reverse increasing of the $\zeta$ potential of quartz.

\subsection{Coagulation of Fine Impurity Particles}

Apart from the heterocoagulation between quartz and impurity particles, the interaction among fine impurity particles was also calculated to analyze the coagulation, which could also influence impurity removal. Figure 11 indicates the interaction energy between hematite and hematite $(\mathrm{H}-\mathrm{H})$, orthoclase and orthoclase $(\mathrm{O}-\mathrm{O})$, orthoclase and hematite $(\mathrm{O}-\mathrm{H})$ under natural condition $(\mathrm{pH}=7)$. The results showed that the $\mathrm{V}_{\mathrm{T}}$ of $\mathrm{O}-\mathrm{O}$ and $\mathrm{O}-\mathrm{H}$ were both positive, while the $V_{T}$ of $\mathrm{H}-\mathrm{H}$ was negative over the whole separation distance, which indicated that the coagulation of fine particles occurred mainly by the formation of homocoagulation between $\mathrm{H}-\mathrm{H}$ in the slurry. 


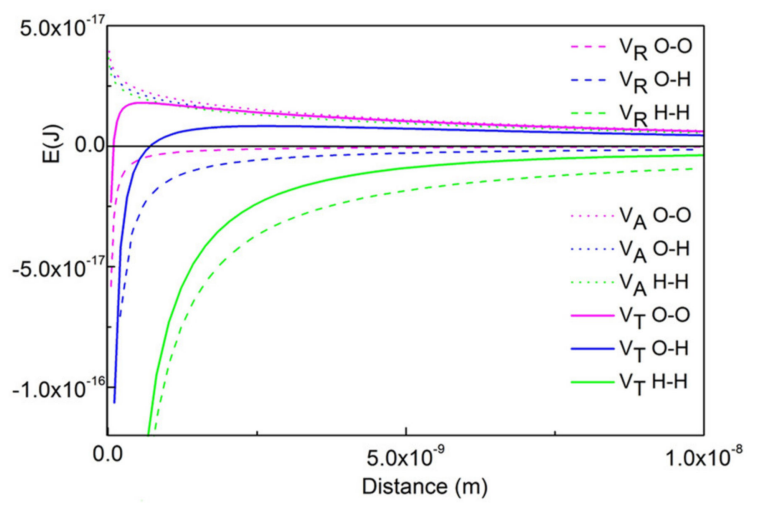

Figure 11. The relationship between interaction energy of fine impurities and particles distances at $\mathrm{pH} 7$.

$V_{T}$ of $\mathrm{H}-\mathrm{H}$ at different $\mathrm{pHs}$ is shown in Figure 12. As can be seen, $V_{T}$ was negative at $\mathrm{pH} 7$ and 8. When the $\mathrm{pH}$ increased to $9, V_{T}$ was close to zero and then changed to positive at $\mathrm{pH} 10$ and 11 . The results indicated that the homocoagulation of $\mathrm{H}-\mathrm{H}$ occurred more easily when the $\mathrm{pH}$ was 7 and 8 , and then became dispersive at $\mathrm{pH}>9$. The conclusion was reinforced by the observation about the stability of slurry of T2, as shown in Figure 13, which showed the settlement of T2 after centrifugation for $24 \mathrm{~h}$ at different $\mathrm{pH}$ values. As can be seen, when the $\mathrm{pH}$ was lower than 9, the fine particles in the slurry were coagulated, and consequently, they settled more easily. On the other hand, when the $\mathrm{pH}$ was over 9 , the slurry became more stable, which was favorable to the removal of these impurities.

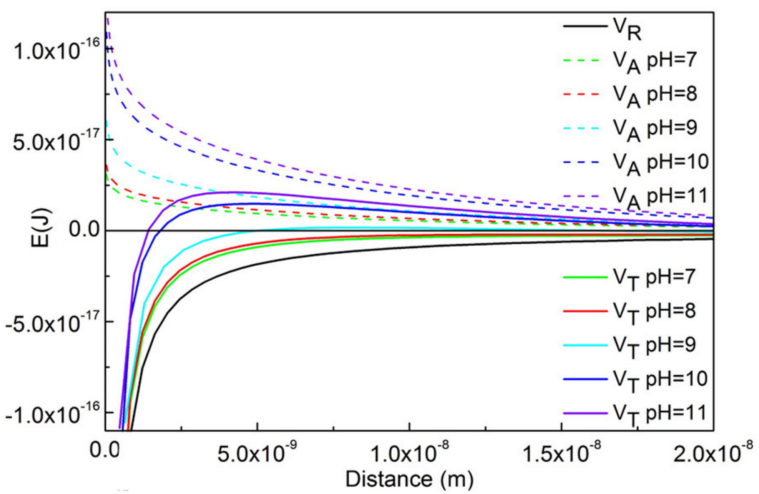

Figure 12. The relationship between interaction energy of $\mathrm{H}-\mathrm{H}$ and particles distance at different $\mathrm{pHs}$.

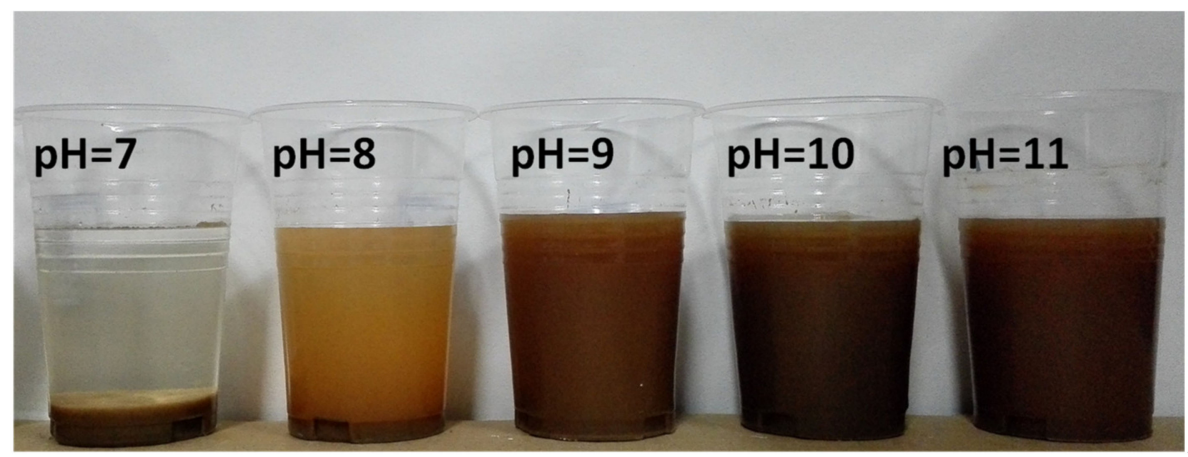

Figure 13. Stability of slurry of $\mathrm{T} 2$ at different $\mathrm{pHs}$.

\subsection{Effects of SHMP on the Zeta Potential and Desliming}

SHMP is a kind of long-chain inorganic salt that has been used as a dispersant for clay mineral separation, which could increase the negative zeta potential of particles, and thus improve the dispersion of slurry $[33,34]$. The $\zeta$ potentials of quartz, hematite and orthoclase were measured 
at the optimized proportion of SHMP $\left(1 \times 10^{3} \mathrm{~g} \cdot \mathrm{t}^{-1}\right)$, according to the previous experiments. As can be seen from Table 5, the addition of SHMP exhibited a remarkable effect on decreasing the $\zeta$ potential of all three minerals. As stated in the previous analysis, the $\zeta$ potentials of minerals were negative enough to lead to a good dispersion of slurry, which is agreement with the impurity removal results, as shown in Figure 8.

Table 5. $\zeta$ potential of quartz, hematite and orthoclase at different dosage of SHMP at $\mathrm{pH} 7$.

\begin{tabular}{cccc}
\hline \multirow{2}{c}{$\zeta$} & \multicolumn{3}{c}{ Dosage of SHMP $/ \mathbf{g} \cdot \mathbf{t}^{-\mathbf{1}}$} \\
\cline { 2 - 4 } & $\mathbf{0}$ & $\mathbf{1 0 0 0}$ & $\mathbf{5 0 0 0}$ \\
\hline Quartz & -51.31 & -56.03 & -38.57 \\
\hline Hematite & -27.01 & -61.83 & -51.23 \\
\hline Orthoclase & -25.56 & -75.07 & -67.57 \\
\hline
\end{tabular}

Moreover, $\zeta$ potentials of quartz, hematite and orthoclase at the dosage of SHMP being $5 \times 10^{3} \mathrm{~g} \cdot \mathrm{t}^{-1}$ were measured to explain the destabilization of impurity removal when excessive SHMP were added. When the dosage of SHMP increased from $1 \times 10^{3} \mathrm{~g} \cdot \mathrm{t}^{-1}$ to $5 \times 10^{3} \mathrm{~g} \cdot \mathrm{t}^{-1}$, as can be seen, $\zeta$ potentials of all three minerals present an inverse increase (absolute value decrease). It should also be noted that the electrical double layers of minerals were significantly compressed at high ionic strengths [35]. All the results indicate that an appropriate dosage of SHMP could improve the removal efficiency of clay impurities in NPQ, but an excessive dosage of SHMP could have a negative impact on the impurity removal, i.e., the same as adjusting $\mathrm{pH}$.

\section{Conclusions}

In summary, scrubbing combining with centrifugation was proven to be an effective method for the desliming purification of NPQ. The removal efficiency of impurities reached an optimal value at $\mathrm{pH}$ 9.3, or when the dosage of SHMP reached $1 \times 10^{3} \mathrm{~g} / \mathrm{t}$. The main impurities of $\mathrm{Fe}_{2} \mathrm{O}_{3}$ and $\mathrm{Al}_{2} \mathrm{O}_{3}$ in the concentrate decreased to less than $0.01 \%$ and $0.02 \%$, respectively. It was concluded that the scrubbing process played an important role in the enhancement of impurities liberation. Then, the addition of regulators such as $\mathrm{NaOH}$ or SHMP could effectively increase the negative $\zeta$ potential of minerals, and thus increase the $V_{T}$, which could effectively decrease the possibility of the heterocoagulation between quartz and impurities, as well as the homocoagulation among hematite particles, consequently improving the removal efficiency of impurities. In conclusion, this technique could be an environment-friendly and highly efficient method for the purification of NPQ.

Author Contributions: Conceptualization, Z.S. and S.Z.; Data Curation, X.D.; Investigation, X.D., C.L. and D.H.; Project Administration, Z.S. and S.Z.; Software, X.D.; Supervision, Z.S. and S.Z.; Writing-Original Draft, X.D.; Writing-Review and Editing, Z.S. and S.Z.

Funding: This research was funded by the Young Elite Scientists Sponsorship Program by CAST (2017QNRC001), the Fundamental Research Funds for the Central Universities (2010YH10 and 2015QH01)

Conflicts of Interest: The authors declare no conflict of interest.

\section{References}

1. Santos, M.F.M.D.; Fujiwara, E.; Schenkel, E.A.; Enzweiler, J.; Suzuki, C.K. Quartz sand resources in the Santa Maria Eterna formation, Bahia, Brazil: A geochemical and morphological study. J. South Am. Earth Sci. 2015, 62, 176-185. [CrossRef]

2. Huang, H.; Li, J.; Li, X.; Zhang, Z. Iron removal from extremely fine quartz and its kinetics. Sep. Purif. Technol. 2013, 108, 45-50. [CrossRef]

3. Prakash, S.; Das, B.; Mohanty, J.K.; Venugopal, R. The recovery of fine iron minerals from quartz and corundum mixtures using selective magnetic coating. Int. J. Miner. Process. 1999, 57, 87-103. [CrossRef] 
4. Zhong, L.L.; Lei, S.M.; Wang, E.W.; Pei, Z.Y.; Li, L.; Yang, Y.Y. Research on Removal Impurities from Vein Quartz Sand with Complexing Agents. Appl. Mech. Mater. 2013, 454, 194-199. [CrossRef]

5. Andrews, P.R.A.; Collings, R.K. Canadian silica resources for glass and foundry sand production: Processing studies at CANMET. Int. J. Miner. Process. 1989, 25, 311-317. [CrossRef]

6. Tuncuk, A.; Akcil, A. Iron removal in production of purified quartz by hydrometallurgical process. Int. J. Miner. Process. 2016, 153, 44-50. [CrossRef]

7. Zhang, Z.; Li, J.; Li, X.; Huang, H.; Zhou, L.; Xiong, T. High efficiency iron removal from quartz sand using phosphoric acid. Int. J. Miner. Process 2012, 114-117, 30-34. [CrossRef]

8. Hou, Y.; Liu, P.; Hou, Q.; Duan, H.; Xie, Y. Study on removal fluid inclusions in quartz sand by microwave explosion. Nanosci. Nanotechnol. Lett. 2017, 9, 151-154. [CrossRef]

9. Štyriakov, A.I.; Štyriak, I.; Kraus, I.; Uhlík, P.; Madejov, A.J.; Orolínov, A.Z. Bioleaching of clays and iron oxide coatings from quartz sands. Appl. Clay Sci. 2012, 61, 1-7. [CrossRef]

10. He, M.S.; Yao, Q.; Yi, Y.Q. Analysis of the development and utilization and the supply and demand situation on Natural powder quartz at Jiang Xi province. China Nonmet. Miner. Ind. 2003, 6, 52-55. (In Chinese)

11. Richard, B.; John, M.M. Geology of Microcrcrystalline Silica (Tripoli) Deposits, Southernmost Illinois. Illinois State Geological Survey. 1994; pp. 4-8. Available online: https://core.ac.uk/download/pdf/ 17355415.pdf (accessed on 27 January 2019).

12. Tan, J.; Zhou, H.; Wang, M.; Zhu, B.Q.; Gao, X.Q.; Zheng, C.H. Study of the purification and whitening of Natural powder quartz. Acta Mineral. Sin. 2014, 34, 7-12. (In Chinese)

13. Zhang, Y.P.; Huang, K.L.; Liu, S.Q. Separation of clinochlore from powder quartz by reverse flotation and its mechanism. J. Cent. South Univ. Technol. (Sci. Technol.) 2007, 2, 285-290. (In Chinese)

14. Bayley, R.W.; Biggs, C.A. Characterisation of an attrition scrubber for the removal of high molecular weight contaminants in sand. Chem. Eng. J. 2005, 111, 71-79. [CrossRef]

15. Stražišar, J.; Sešelj, A. Attrition as a process of comminution and separation. Powder Technol. 1999, 105, $205-209$. [CrossRef]

16. Sun, Z.; Yang, X.; Zhang, G.; Zheng, S.; Frost, R.L. A novel method for purification of low grade diatomite powders in centrifugal fields. Int. J. Miner. Process. 2013, 125, 18-26. [CrossRef]

17. Batalović, V. Centrifugal separator, the new technical solution, application in mineral processing. Int. J. Miner. Process. 2011, 100, 86-95. [CrossRef]

18. Kang, S.; Zhao, Y.; Wang, W.; Zhang, T.; Chen, T.; Yi, H.; Rao, F.; Song, S. Removal of methylene blue from water with montmorillonite nanosheets/chitosan hydrogels as adsorbent. Appl. Surf. Sci. 2018, 448, $203-211$. [CrossRef]

19. Petruk, W. Automatic Image Analysis for Mineral Beneficiation. JOM 1988, 40, 29-31. [CrossRef]

20. Fandrich, R.; Gu, Y.; Burrows, D.; Moeller, K. Modern SEM-based mineral liberation analysis. Int. J. Min. Process. 2007, 84, 310-320. [CrossRef]

21. Houta, N.; Lecomte-Nana, G.L.; Tessier-Doyen, N.; Peyratout, C. Dispersion of phyllosilicates in aqueous suspensions: Role of the nature and amount of surfactant. J. Colloid Interface Sci. 2014, 425, 67-74. [CrossRef] [PubMed]

22. Yu, Y.; Ma, L.; Xu, H. DLVO theoretical analyses between montmorillonite and fine coal under different $\mathrm{pH}$ and divalent cations. Powder Technol. 2018, 330, 147-151. [CrossRef]

23. Israelachvili, J.N. Intermolecular and Surface Forces, 3rd ed.; Academic Press: New York, NY, USA, 1985; p. 262.

24. Berg, J.C. An Introduction to Interfaces \& Colloids: The Bridge to Nanoscience; World Scientific: Singapore, 2010.

25. Robinson, D. Measurement of the solid dielectric permittivity of clay minerals and granular samples using a time domain reflectometry immersion method. Vadose Zone J. 2004, 3, 705-713. [CrossRef]

26. Marland, S.; Merchant, A.; Rowson, N. Dielectric properties of coal. Fuel 2001, 80, 1839-1849. [CrossRef]

27. Kaya, A.; Yukselen, Y. Zeta potential of clay minerals and quartz contaminated by heavy metal. Can. Geotech. J. 2005, 42, 1280-1289. [CrossRef]

28. Yukselen-Aksoy, Y.; Kaya, A. A study of factors affecting on the zeta potential of kaolinite and quartz powder. Environ. Earth Sci. 2011, 62, 697-705. [CrossRef]

29. Rohem Peçanha, E.; da Fonseca de Albuquerque, M.D.; Antoun Simão, R.; de Salles Leal Filho, L.; de Mello Monte, M.B. Interaction forces between colloidal starch and quartz and hematite particles in mineral flotation. Colloid Surf. A Physicochem. Eng. Asp. 2019, 562, 79-85. [CrossRef] 
30. James, R.O.; Healy, T.W. Adsorption of hydrolyzable metal ions at the oxide-Water interface. II. Charge reversal of $\mathrm{SiO}_{2}$ and $\mathrm{TiO}_{2}$ colloids by adsorbed $\mathrm{Co}(\mathrm{II}), \mathrm{La}(\mathrm{III})$, and $\mathrm{Th}(\mathrm{IV})$ as model systems. J. Colloid Interface Sci. 1972, 40, 53-64. [CrossRef]

31. Li, Z.-Y.; Xu, R.-K.; Li, J.-Y.; Hong, Z.-N. Effect of clay colloids on the zeta potential of Fe/Al oxide-coated quartz: A streaming potential study. J. Soils Sediments 2016, 16, 2676-2686. [CrossRef]

32. Rodríguez, K.; Araujo, M. Temperature and pressure effects on zeta potential values of reservoir minerals. J. Colloid Interface Sci. 2006, 300, 788-794. [CrossRef] [PubMed]

33. Espinozaortega, O. Role of Sodium Hexametaphosphate in the Flotation of Acanthite Fines from Finely Disseminated Ores. Sep. Sci. Technol. 2009, 44, 2971-2982.

34. Zhang, T.; Vandeperre, L.J.; Cheeseman, C.R. Formation of magnesium silicate hydrate (M-S-H) cement pastes using sodium hexametaphosphate. Cem. Concr. Res. 2014, 65, 8-14. [CrossRef]

35. Tiller, C.L.; O'Melia, C.R. Natural organic matter and colloidal stablility: Models and measurements. Colloid Surf. A Physicochem. Eng. Asp. 1993, 73, 89-102. [CrossRef]

(C) 2019 by the authors. Licensee MDPI, Basel, Switzerland. This article is an open access article distributed under the terms and conditions of the Creative Commons Attribution (CC BY) license (http:/ / creativecommons.org/licenses/by/4.0/). 